\title{
WATER VAPOR MIXING RATIO DISTRIBUTION INVERSION BY RAMAN LIDAR IN BEIJING
}

\author{
SiQi Yu ${ }^{1,2}$, Dong Liu ${ }^{2}$, JiWei $\mathrm{Xu}^{2}$, ZhenZhu Wang ${ }^{2}$, DeCheng $\mathrm{Wu}^{2}$, Yingjian Wang ${ }^{2,1}$ \\ ${ }^{1}$ School of Environmental Science and Optoelectronic Technology, University of Science and \\ Technology of China, Hefei, Anhui 230026, China \\ ${ }^{2}$ Key Laboratory of Atmospheric optics, Anhui Institute of Optics and Fine Mechanics, Chinese Academy \\ of Sciences, Hefei, Anhui 230031, China \\ *Email:dliu@aiofm.ac.cn
}

\begin{abstract}
Water Aerosol Raman Lidar-II is an active detection instrument with high temporal and spatial resolution at Nanjiao observation station, and that could continuous water vapor mixing ratio (WVMR) measurements. WVMR profiles inversion from lidar data and water ratio retrieved from radiosonde data are in good agreement. The statistical results of the vertical distribution of WVMR indicate that WVMR seasonal mean distribution is consistent with precipitation. In addition, WVMR in Nanjiao station is related to total cloud cover.
\end{abstract}

\section{INTRODUCTION}

Water vapor plays a very important role at climate change. Global water vapor amounts increase in a warmer climate, leading to a positive feedback via its enhanced greenhouse effect ${ }^{[1]}$. Lidars (DIAL and Raman) are the only instruments available for high temporal and vertical resolution of continuous WVMR measurements ${ }^{[2]}$. What's more, obtaining a dataset of atmospheric water vapor content with high spatial and temporal coverage conduce to understand the vertical structure ${ }^{[3]}$.

In the current study, the water vapor mixing ratio profiles obtained by the means of Water Aerosol Raman Lidar-II in Nanjiao station. Observation period from September 2017 to August 2018. The lidar and the data set, as well as the inversion approach to get water vapor mixing ratio and water ratio are described in Section 2. The results are presented in Section 3, including the relationship between water vapor mixing ratio and water ratio, as well as the statistical results of water vapor mixing ratio.

\section{METHODOLOGY}

\subsection{Experimental site and instrumentation}

The instrument used to detect atmosphere is Water Aerosol Raman Lidar-II (named as WARLII), which has been installed at the Nanjiao observation station, Beijing, China. Nanjiao station $(39.81 \mathrm{~N}, 116.48 \mathrm{E})$ located in North China Plain, which experiences distinct seasons, namely, winter (December, January and February), spring (March, April and May), summer (June, July and August) and autumn (September, October and November). Figure1 gives the schematic diagram of WARL-II system. WARL-II emits at $532 \mathrm{~nm}$ (output energies per pulse of $150 \mathrm{~mJ}$ ) and receive elastic channels at parallel and perpendicular polarization channels at $532 \mathrm{~nm}$ as well as Raman-shifted channels at $607 \mathrm{~nm}$ (from $\mathrm{N}_{2}$ ) and $660 \mathrm{~nm}$ (from $\mathrm{H}_{2} \mathrm{O}$ ). The spatial and temporal resolution of WARL-II is $7.5 \mathrm{~m}$ and 5minutes, respectively. The ground-based passive device continuously measured aerosol and cloud vertical distribution and humidity profiles during the studied period.

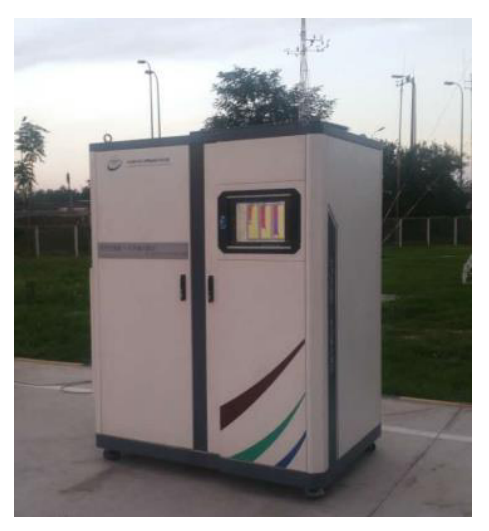




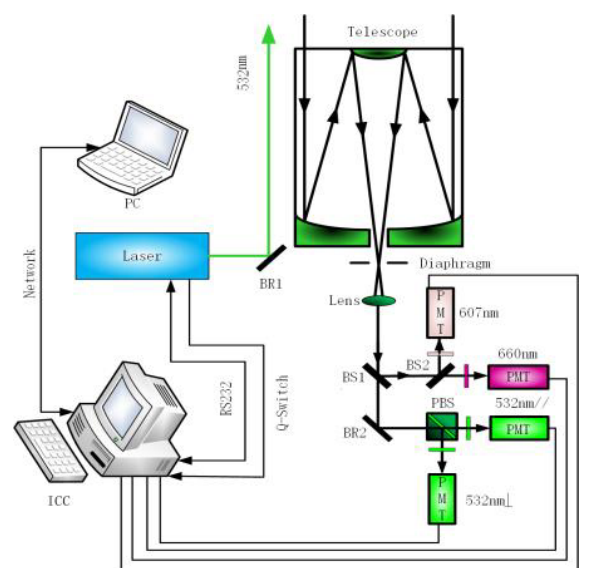

Figure 1 The schematic diagram and photo of WARL- II

Table 1 Specification of WARL- II

\begin{tabular}{ll}
\hline Characteristic & Value \\
\hline Transmitter & \\
\hline Wavelength & $532 \mathrm{~nm}$ \\
\hline Pulse Energy & $150 \mathrm{~mJ}$ \\
\hline Pulse Width & $<6 \mathrm{~nm}$ \\
\hline Pulse frequency & $10 \mathrm{~Hz}$ \\
\hline Divergence & $<0.5 \mathrm{mrad}$ \\
\hline Receiver & \\
\hline Type of telescope & Cassegrain \\
\hline Diameter & $\sim 300 \mathrm{~mm}$ \\
\hline FOV & $0.5-2 \mathrm{mrad}$ \\
\hline receive wavelength & $532 \mathrm{~nm}, 607 \mathrm{~nm}, 660 \mathrm{~nm}$ \\
\hline Filter bandwidth & $\sim 1 \mathrm{~nm}$ \\
\hline Optical sensor & PMT \\
\hline Data Acquisition & \\
\hline Resolution & $16 \mathrm{bit}$ \\
\hline
\end{tabular}

The department of atmospheric sciences of University of Wyoming has a radiosonde database for the whole world. The Beijing observation $(39.93 \mathrm{~N}, 116.28 \mathrm{E})$ is about $21 \mathrm{~km}$ away from Nanjiao station. The radiosonde data obtained twice a day, at local standard time 8:00 and 20:00 respectively. The soundings are available on $\mathrm{http}: / /$ weather.uwyo. edu/upperair/sounding.html.

\section{2 inversion method}

\subsubsection{Ground-based LIDAR}

The Raman lidar is an efficient measurement tool of the mixing ratio of water vapor to dry air. A classical retrieval approach of water vapor mixing ratio(WVMR) provided by Ansmamn et al. ${ }^{[4]}$ at 1992 , which can be defined as follows ${ }^{[5]}$ :

$m(z)=K_{m} \frac{P_{\lambda 660}}{P_{\lambda 607}} \times \frac{\exp \left\{-\int_{0}^{z}\left[\alpha_{\lambda 607}^{a e r}(z)+\alpha_{\lambda 607}^{m o l}(z)\right] d z^{\prime}\right\}}{\exp \left\{-\int_{0}^{z}\left[\alpha_{\lambda 660}^{a e r}(z)+\alpha_{\lambda 660}^{m o l}(z)\right] d z^{\prime}\right\}}$

Where, the $\mathrm{P}_{\lambda}$ denotes the Raman-shifted return lidar signals from distance $\mathrm{z}$ at the laser wavelength $\lambda$ for the water vapor $(660 \mathrm{~nm})$ and the nitrogen $(607 \mathrm{~nm})$. The $\boldsymbol{\alpha}$ denotes the light extinction at wavelength $\lambda$, as well as 'aer' and 'mol' is represent for aerosol extinction and molecular extinction respectively. The water vapor mixing ratio calibration constant $\mathrm{K}_{m}=\frac{K_{\lambda 607}}{K_{\lambda 660}}$ could determine from a comparison of the lidar measurement with critically evaluated data from a radiosonde ascent.

Generally, the Raman signal are operated more conveniently during night time. This is because, the lidar return signal is dominated by noise during day-time.

\subsubsection{Radiosondes}

The Radiosonde water ratio(WR) profile retrieval is according to equation $(2,3)$, which are used by $\mathrm{Wu}$ et al.2016 $6^{[6]}$.

$\mathrm{WR}=\mathrm{RH} * \mathrm{~S}=\mathrm{RH} * \frac{0.622 * P_{S}(T)}{P-0.378 * P_{S}(T)}$

$P_{S}(T)=6.1121 * \exp \left(\left(18.678-\frac{T}{234.5}\right) *\right.$

$\left.\left(\frac{T}{257.14+T}\right)\right)$

Where, RH denotes relative humidity, $\mathrm{S}$ denotes specific humidity. $\mathrm{P}$ is the atmospheric pressure, and $P_{S}$ is the saturated vapor pressure $(\mathrm{mb})$ at temperature $\mathrm{T}\left({ }^{\circ} \mathrm{C}\right)$ and can be calculated by equation(3).

\section{RESULTS}




\subsection{COMPARISON RESULTS}

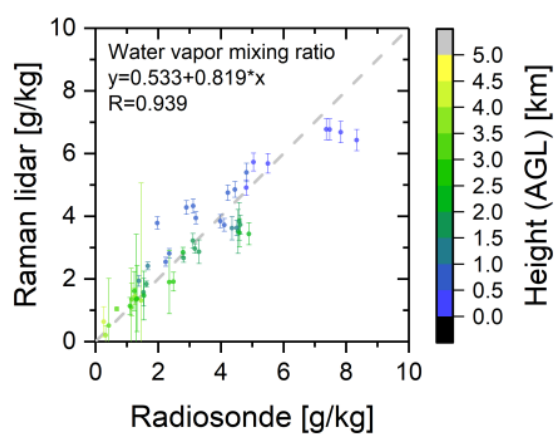

Figure 2 regression of water vapor mixing ratio profile to radiosonde measurement

Figure 2 is the comparison results between WARLII and radiosonde. It is obtained for profile by the linear regression method. The regression analysis results used the data of three days of October ,2017, 13,19 and 23 respectively. The correlation coefficient is 0.939 and that means the calibration of WARL-II measurement can give a reasonably accurate estimate of water vapor profile for the routine observation.

\section{2 statistical results of water vapor vertical distribution}
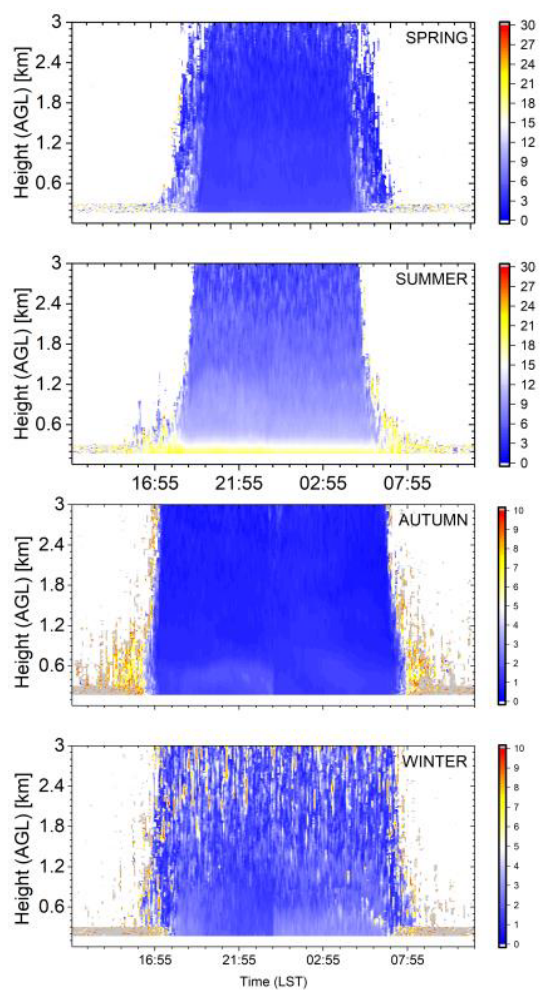

Figure 3 WVMR vertical distribution at difference seasons
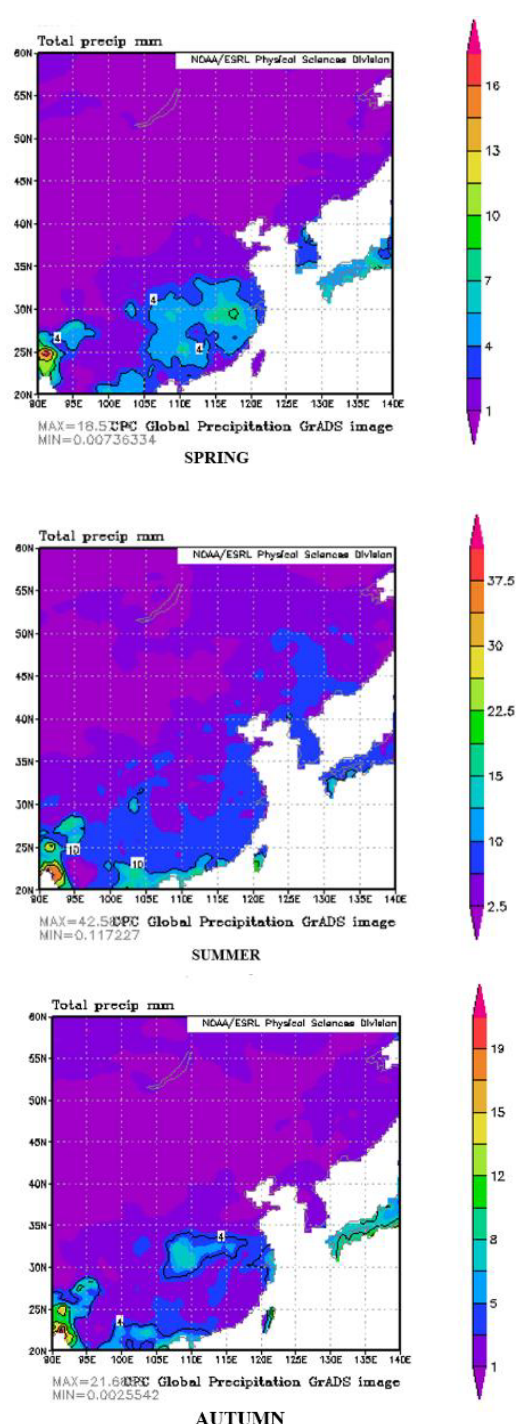

AUTUMN

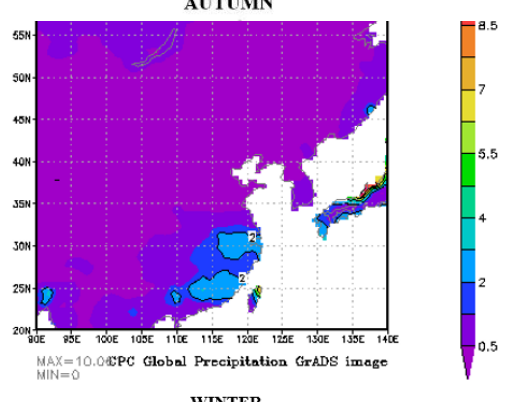

Figure 4 seasonal mean precipitation

As shown in Figure 3, statistical analysis results of Water Vapor Mixing Ratio (WVMR) measured by lidar among spring, summer, autumn and winter. Atmospheric observations of autumn were performed from 1 September to 30 November 2017. The period of winter is between 00:00 LST on 1 December 2017 and 24:00 LST on 28 
February 2018. Spring is from 00:00 LST on 1 March 2018 to 24:00 LST on 31 May 2018. Summer, the last season of observation, ending at 24:00 LST on 31 August 2018. The seasonal mean values of WVMR in spring, summer, autumn, winter are range from 0 to $9 \mathrm{~g} / \mathrm{kg}, 8$ to $18 \mathrm{~g} / \mathrm{Kg}, 1$ to $8 \mathrm{~g} / \mathrm{Kg}, 0$ to $3 \mathrm{~g} / \mathrm{Kg}$, respectively. These observation results are consistent with the consequence of Wang et al. ${ }^{[7]}$. Nanjiao station is at the monsoon zone, which with seasonal rainfall variability. In order to explain the relationship of water vapor mixing ratio and precipitation, seasonal mean precipitation at $116.48 \mathrm{E}, 39.81 \mathrm{~N}$ from the National Center for Environmental Prediction/National Center for Atmospheric Research (NCEP/NCAR) Reanalyzed data are examined in Fig. 4. The four seasons of Figure 4 cover the same time period of lidar observation. According to Figure 3 and figure 4, water vapor mixing ratio measured by lidar have a good consistency with precipitation. The nocturnal value of WVMR in summer is the largest, while in winter is minimum. The reason for the difference obvious for the monsoon.

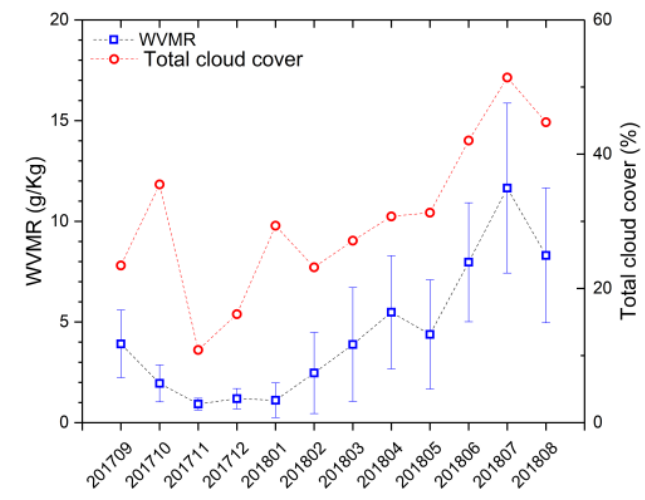

Figure 5 water vapor mixing ratio (WVMR) and total cloud cover

Figure 5 reveals the correlation between monthly mean WVMR and monthly mean total cloud cover. To ensure the accuracy of the measurement, the measured the water vapor profiles measured by WARL-II statistic from 00:00 LST to 06:00 LST and 18:00 LST to 24:00LST. The data of monthly mean total cloud cover is from (NCEP/NCAR) website. Exclude October 2017 and January 2018, red line and blue line have consistent trend. Frequency that occurs during the day of Clouds may contribute to the result.

\section{ACKNOWLEDGEMENTS}

This work was s supported by the Science and Technology Service Network Initiative of CAS (KFJ-STS-QYZD-022).

Thanks to the NCEP/NCAR for the Reanalyzed data. As well as thanks to University of Wyoming for radiosonde data.

\section{REFERENCES}

1. Boucher, O., et al., Clouds and aerosols, in Climate change 2013: the physical science basis. Contribution of Working Group I to the Fifth Assessment Report of the Intergovernmental Panel on Climate Change. 2013, Cambridge University Press. p. 571-657.

2. Filioglou, M., et al., Profiling water vapor mixing ratios in Finland by means of a Raman lidar, a satellite and a model. Atmospheric Measurement Techniques, 2017. 10(11): p. 123.

3. Fujita, M. and T. Sato, Observed behaviours of precipitable water vapour and precipitation intensity in response to upper air profiles estimated from surface air temperature. Sci Rep, 2017. 7(1): p. 4233.

4. ANSMANN, et al., Combined Raman elasticbackscatter LIDAR for vertical profiling of moisture, aerosol extinction, backscatter, and LIDAR ratio. Applied Physics B, 1992. 55(1): p. 18-28.

5. Stachlewska, I.S., M. Costa-Surós, and D. Althausen, Raman lidar water vapor profiling over Warsaw, Poland. Atmospheric Research, 2017. 194: p. 258-267.

6. Wu, S., et al., Observations of water vapor mixing ratio profile and flux in the Tibetan Plateau based on the lidar technique. Atmospheric Measurement Techniques,9,3(2016-04-01), 2016. 8(11): p. 11925-11952.

7. Wei, W., et al., Long-Term Measurement for Low-Tropospheric Water Vapor and Aerosol by Raman Lidar in Wuhan. Atmosphere, 2015. 6(4): p. 521-533. 